PONTIFÍCIA UNIVERSIDADE CATÓLICA DO RIO DE JANEIRO

\title{
A diferença entre homens e mulheres no mercado financeiro na perspectiva das mulheres
}

Jéssica Castro

Trabalho de Conclusão de Curso

Centro de Ciências Socials - CCS

DEPARTAMENTO DE AdMINISTRAÇÃO

Graduação em Administração de Empresas 


\section{A diferença entre homens e mulheres no mercado financeiro na perspectiva das mulheres}

Trabalho de Conclusão de Curso

Trabalho de Conclusão de Curso, apresentado ao programa de graduação em Administração da PUC-Rio como requisito parcial para a obtenção do titulo de graduação em Administração.

Orientador (a): Edmundo Eutrópico

Rio de Janeiro

Novembro de 2018. 


\section{Resumo}

Castro, Jéssica. A diferença entre homens e mulheres no mercado financeiro na perspectiva das mulheres. Rio de Janeiro, 2018. Número de páginas 42 p. Trabalho de Conclusão de Curso - Departamento de Administração. Pontifícia Universidade Católica do Rio de Janeiro.

Este artigo analisa o desempenho da mulher executiva, assalariada, e que decidiram pela carreira nos setores de bancos de investimento, mercados de capitais e serviços financeiros no Brasil. O presente estudo apresentará, através de uma amostra de 10 entrevistadas, o dia-a-dia da mulher no mercado para testar algumas ideias quanto a atuação feminina, o sentimento das mulheres frente ao conceito e existência da discriminação no ambiente laboral. Buscamse, também, as razões da discriminação da mão-de-obra feminina, por parte das modernas organizações, dos clientes, fornecedores e gestores. Com isso, os mesmos terão maior conhecimento para iniciar ações que valorizem essa mão de obra e as próprias mulheres terão exemplos de atitudes e vivencias que contribuirão para seu caminho profissional. $\mathrm{Na}$ revisão da literatura foram apresentados diversos fatores que influenciaram e colaboraram para a construção da visão da mulher diante da sociedade, o movimento feminista, a divisão sexual do trabalho e os avanços obtidos pela legislação. Através da pesquisa qualitativa e do método de pesquisas exploratória, foram efetuadas entrevistas com mulheres e analisados os dados e informações coletadas por revistas, jornais, livro e outras artigos e dissertações sobre o assunto.

\section{Palavras-chave}

Mercado Financeiro, carreira, Equidade de gênero, Mercado de trabalho.

\section{Abstract}

Castro, Jéssica. The difference between men and women in the financial market from the perspective of women. Rio de Janeiro, 2018. 42 p. Trabalho de Conclusão de Curso - Departamento de Administração. Pontifícia Universidade Católica do Rio de Janeiro. 
This article analyzes the performance of the salaried executive woman who decided to pursue careers in the investment banking, capital markets and financial services sectors in Brazil. The present study will present, through a sample of 10 interviewees, the daily life of the woman in the market to test some ideas about the female performance, the women's feeling about the concept and existence of discrimination in the work environment. The reasons for the discrimination of the female labor force are also sought by modern organizations, customers, suppliers and managers. With this, they will have greater knowledge to initiate actions that value this workforce and the women themselves will have examples of attitudes and experiences that will contribute to their professional path. In the review of the literature, several factors that influenced and collaborated to construct the vision of women before the society, the feminist movement, the sexual division of labor and the advances obtained by the legislation were presented. Through qualitative research and the exploratory research method, interviews were conducted with women and data and information collected by magazines, newspapers, books and other articles and dissertations were analyzed.

Key words

Financial Market, Women's Career, Gender Equity, Equal Opportunity. 


\section{Sumário}

1. A diferença entre homens e mulheres no mercado financeiro na perspectiva das mulheres 1

1.1. A Mulher no Mercado Financeiro 2

1.2. Objetivo do estudo 2

1.3. Delimitação e foco do estudo 3

1.4. Relevância do Estudo 3

2. Revisão de literatura 5

2.1. A Inserção da Mulher no Direito do Trabalho 5

2.2. O Trabalho da Mulher no Brasil 8

3. As Principais Influencias na construção da visão da mulher 9

3.1.1. A lgreja 9

3.1.2. A Educação 10

3.1.3. Os meios de comunicação e a publicidade 11

4. Métodos e procedimentos de coleta e de análise de dados do estudo13

5 . Apresentação e análise dos resultados 15

5.1. Perfil das Entrevistada 15

5.2. O Ingresso e a Ascensão Profissional 16

$\begin{array}{ll}\text { 5.3. Diversidade de rendimentos } & 17\end{array}$

$\begin{array}{ll}\text { 5.4. Equidade de gênero } & 17\end{array}$

5.5. A Valorização das Mulheres 18

5.6. Baixa Representação das Mulheres 18

$\begin{array}{ll}\text { 5.7. Discriminação no Trabalho } & 19\end{array}$

6. Conclusões e recomendações para novos estudos 21

7. Referências Bibliográficas 23 
Anexo 1: Roteiro das Entrevistas

Anexo 2: Transcrição das Entrevistas 


\section{A diferença entre homens e mulheres no mercado financeiro na perspectiva das mulheres}

Inicia-se em meados do século XX o crescimento da participação das mulheres no mercado de trabalho, principalmente com o movimento feminista e seus desdobramentos. Apesar de todas essas conquistas, as mulheres ainda sofrem discriminação sendo pior remuneradas e ocupando menos cargos de destaques que os homens seja qual for seu nível de instrução. (KOMETANI, G1, 2017)

Com intuito de assegurar a igualdade de oportunidades, o Governo Federal criou o Programa Pró-Equidade de Gênero da Secretaria Especial de Políticas para as Mulheres (SPM), para conscientizar e sensibilizar os empregadores a estimular as práticas de igualdade de oportunidades entre os gêneros e as relações de trabalho sem descriminação contra a mulher dentro das organizações. (BNDES, 2018)

Este trabalho de conclusão de curso busca colaborar com as mulheres, gestores e empresas que não mapearam os desafios e vivencias das profissionais do mercado financeiro. Segundo Pesquisa Nacional por Amostra de Domicílios (PND), terceiro trimestre de 2016, as mulheres representam mais de $43,3 \%$ da população economicamente ativa no país e a taxa dos ocupados com ensino superior completo, médio feminino, equivale a apenas $58,1 \%$ do rendimento médio masculino, sendo as Taxa de Assalariamento, em média, $75,0 \%$ do que os homens ganham. Já para o crescimento profissional, 50,4\% das mulheres estão empregadas no setor privado com carteira, contra $72,4 \%$ do sexo masculino e a taxa de desemprego médio entre mulheres é mais alta do que entre homens (CARTA CAPITAL, 2018). Além disso, mulheres ganham 58\% menos que os homens para fazer a mesma jornada e tipo de serviço, dados do Relatório Global Gender Gap (TERRA,2018), Fórum Econômico Mundial.

Segundo a (Organização Internacional do Trabalho,2016) um fator positivo em relação ao Brasil e que temos uma diferença percentual entre os gêneros um pouco menor do que no resto do mundo, o país está na 92º posição em 159 países no Índice de Desigualdade de Gênero (ISTOÉ.Gender Inequality Index GII, 2017). 
Estimativas da OIT apontam que a inserção da mulher no mercado de trabalho contribuiria na expansão econômica em até $R \$ 382$ bilhões em oito anos (BBC Brasil, 2017).

\subsection{A Mulher no Mercado Financeiro}

Apesar do crescimento da mulher no mercado de trabalho, o setor financeiro possui um número muitos baixos de mulheres, assim como outras áreas que ainda são consideradas masculinas. (YAHOO! FINANÇAS, 2018)

De acordo com a BM\&F Bovespa, houve crescimento na participação de mulheres na Bolsa de Valores do país que conta com mais de 130 mil investidoras. (ESTADÃO, 2017).

Segundo estudo publicado pela Bloomberg, as mulheres costumam lidar melhor com as instabilidades do mercado financeiro, até em momentos conturbados. Já a pesquisa da empresa de investimentos europeia Nutmeg Saving and Investment Ltd, mostra que a desistência da aplicação financeira no mercado desestabilizado é quatro vezes maior no homem do que na mulher. A Nutmeg analisou seis anos de mudanças bruscas de preço do FTSE 100, e entre 50 mil investidores do Reino Unido, as investidoras tenderam a manter-se firmes durante eventos turbulentos como a dívida grega, em 2013, e a alta de juros nos Estados Unidos de fevereiro de 2018. (O GLOBO Economia, 2018)

Apesar do crescimento das mulheres nesse mercado e da avaliação positiva de suas qualificações e características, conforme apostado acima, ainda há desafios ao ingressar no mercado e construir uma carreira. As trabalhadoras desse mercado encaram julgamentos quanto a sua idade, o gênero e a capacidade profissional. Por isso, qualquer descuido na fala ou vestuário pode afetar a sua credibilidade profissional.

\subsection{Objetivo do estudo}

O objetivo do presente estudo é analisar as percepções, vivências e experiências das mulheres, tendo em consideração a igualdade de trabalho e oportunidades no Mercado Financeiro. Buscou-se entender e levantar a questão da percepção individual e pessoal das mulheres para avaliar se a desigualdade é um fenómeno real e se há diferenças entre as áreas no mercado financeiro.

Tentou-se, também, compreender o sentimento das mulheres e como julgam ser vistas no Mercado Financeiro em relação à maternidade, aos direitos 
iguais, à relação com os gestores e clientes, à remuneração, às oportunidades de crescimento e o respeito recebido por todos dessa área.

\subsection{Delimitação e foco do estudo}

O recorte utilizado consistiu em mulheres, ativas, que fizeram ou estão iniciando sua carreira nos setores de bancos de investimento, mercados de capitais e serviços financeiros no Rio de Janeiro, Brasil. A idade das entrevistadas varia entre 18 e 60 anos, independente da área exercida dentro do mercado financeiro. Foram realizadas 10 entrevistas nos locais de trabalho das entrevistadas ou através de contatos telefônicos. As entrevistadas foram escolhidas através da proximidade ou recomendação. Buscou-se em todo momento minimizar qualquer viés ligado ao feminismo ou qualquer opção ideológica, para captar as vivencias mais verídicas e imparciais.

\subsection{Relevância do Estudo}

Este trabalho de conclusão busca contribuir com todos os envolvidos desse mercado (mulheres, organizações e Estado), para conscientizar sobre a temática associada a percepção da mulher sobre à igualdade de trabalho para que sejam desenvolvidas práticas para melhores condições de trabalho.

A relevância deste estudo justifica-se como uma forma de verificar se a equidade do trabalho tem sido aplicada no dia a dia das mulheres e identificar os obstáculos informais que impedem sua fixação na sociedade.

Pretende-se colaborar para que as mulheres possam se consciencializar sobre os seus direitos e sobre a pertinência das sua ambição e interesse no mercado de trabalho no setor financeiro.

A análise deste trabalho poderá, para as organizações, ser uma ferramenta de desenvolvimento social, contribuindo para as relações internas e na formação do seu corpo de colaboradores, permitindo sustentar a diversidade e a promoção do crescimento individual. Esta mudança de postura ou de cultura da empresa poderá trazer benefícios para homens, mulheres e todos os envolvidos nesse mercado. Potenciais que são bem aproveitados independente do seu gênero, tornam as equipes mais eficientes, aumenta o grau de satisfação dos funcionários e, com isso, os resultados alcançados pela empresa tendem a ser melhores. 
Para o Estado, o estudo poderá permitir, como forma de reforçar os mecanismos de promoção da igualdade, monitorizar a aplicação legislativa com um olhar voltado para as reais necessidades e percepções da mulher. 


\section{Revisão de literatura}

\subsection{A Inserção da Mulher no Direito do Trabalho}

Apesar de estar sempre presente, já que primeiros registros são antes do período pós-abolição e da revolução, o trabalho da mulher sempre esteve limitado pela divisão de gênero no trabalho, podemos destacar como exemplo a sua presença majoritária na indústria têxtil no final do século XIX. (PEREIRA, industrial Instituto de Pesquisas Econômicas Aplicadas, 2017)

Essa discriminação e exclusão da mulher vem desde o modelo colonizador europeu. O estereótipo da figura feminina era reforçado pela supervalorização da intimidade e da maternidade, por isso a mulher era limitada ao meio privado. Sua educação era focada, além da leitura e escrita, em tarefas domésticas como cozinhar, lavar e costurar, enquanto os homens possuíam matérias de ciências e matemática. (PEREIRA, industrial Instituto de Pesquisas Econômicas Aplicadas, 2017)

As primeiras leis brasileiras reguladoras das relações de trabalho, como a Lei do Ventre Livre de 1.871 e a Lei de Locação de Serviços de 1.879 , não consideravam a força de trabalho da mulher. (IPEA, 2014)

A primeira constituição brasileira, datada de 1824, não abordava sobre a igualdade entre os gêneros ou sobre o trabalho da mulher. Posteriormente, a Constituição de 1891 continuava neutra sobre o trabalho da mulher e sobre a igualdade entre os gêneros. (PEREIRA, 2017)

No início do século $X X$, com a modernização das relações de trabalho, a mão de obra feminina foi ao lar, sendo responsável por cuidar da casa e da sua família, enquanto os homens estavam no mercado de trabalho. Esse novo confinamento, mostrava os homens pautados como parâmetro de direito, mantendo até hoje o privilégio de atuar tanto na esfera pública quanto na esfera privada. (PEREIRA, 2017)

Os filósofos e pensadores iluministas do século XVIII consideravam a mulher como um ser inferior físico, biológico, intelectual; sustentando a superioridade masculina e dependência da mulher ao homem. O mesmo conceito era aplicado na medicina social brasileira, fim do século XIX e o início do século $X X$, onde a mulher era definida como frágil, com o predomínio do 
emocional sobre o intelectual, vocação materna e submissão. As mulheres na época eram separadas do meio público pelos juristas por ser considerado o comportamento ideal de uma mulher. (PEREIRA, 2017)

O Código Civil de 1916 que reproduzindo a sociedade patriarcal desta época, concedeu ao homem o comando exclusivo da família conforme redação original do caput do seu artigo 233: "O marido é o chefe da sociedade conjugal" e do artigo 240: " A mulher assume, pelo casamento, com os apelidos do marido, a condição de sua companheira, consorte e auxiliar nos encargos da família (art. 324). " Já o artigo 242 do referido código apresentava atos que a mulher não poderia praticar sem autorização do marido, dentre eles, o exercício da profissão, sob pena de nulidade do instrumento, de acordo com o artigo 147 do Código Civil Brasileiro de 1916, sendo estabelecida no artigo 233, IV desta norma, de que o provimento do lar é uma incumbência marital. (BRASIL. Código Civil dos Estados Unidos do Brasil. 1916.)

Em 1917 foi publicada a primeira norma brasileira que se dedicou a tratar especificamente do trabalho da mulher. Trata-se da Lei Estadual oㅜ 1.596, do Estado de São Paulo, que instituindo o Serviço Sanitário do Estado, proibiu o trabalho das mulheres nos estabelecimentos industriais no último mês de gestação e no primeiro puerpério. (BRASIL. Código Civil dos Estados Unidos do Brasil. 1916.)

Em 1923 foi a primeira norma federal dedicada ao trabalho da mulher. $O$ Decreto ํo 16.300 que regulava o Departamento Nacional da Saúde Pública, daria direito a escolha de repouso de trinta dias antes e após o parto, com intervalo para a amamentação de seus filhos.

O processo de entrada no mercado de trabalho, foi diferente para homens e mulheres. As mulheres conjugavam a jornada doméstica com a de trabalho, ou se transformando em donas do lar sem nenhuma renda própria. (PEREIRA, 2017)

Em 1932 foi publicado o Decreto no 21.417 de 1932, o qual regulava o trabalho da mulher nos estabelecimentos comerciais e industriais, garantindo às trabalhadoras um repouso de quatro semanas antes e após o parto, sendo de ente público ou particular e o artigo 13 do decreto proibia a demissão da mulher grávida sem motivo que justifique a dispensa. (PEREIRA, 2017)

No mesmo ano foi publicado o Código Eleitoral - Decreto no 21.076 de 24 de fevereiro de 1932, conferindo a mulher o direito ao voto aos vinte e um anos de idade, posteriormente, reduzida para dezoito anos na Constituição Federal de 1934. A Constituição Federal de 1934 foi a primeira a assegurar a igualdade 
salarial entre as mulheres e os homens, o trabalho da mulher em condições insalubres e a proteção à maternidade, mantendo a mesma lógica traçada pelo Decreto nํ. 21.417 de 1932. (BRASIL. Constituição (1934). 1934)

$\mathrm{Na}$ Constituição Federal de 1937, não reproduziu em seu texto o dispositivo que assegurava a igualdade salarial entre os gêneros, abrindo margem, deste modo, para o tratamento discriminatório. Sendo assim, foi publicado o Decreto-lei no 2.548 de 1940, o qual positivou a discriminação salarial, permitindo em seu artigo $2^{\circ}$ que fosse pago à mulher $10 \%$ a menos que o valor do salário mínimo. (PEREIRA, 2017)

Em 1943, durante o período de crescente industrialização do Brasil, foi aprovada a Consolidação das Leis do Trabalho, por meio do Decreto Lei $\mathrm{n}^{\mathrm{o}}$ 5.452, garantindo a isonomia salarial entre homens e mulheres e no parágrafo único do artigo 446 da CLT que autorizava tanto o pai quanto o marido a pleitear a rescisão do contrato de trabalho da mulher e também trazia proibição de horas extras e de trabalho em horário noturno para a mulher. (PEREIRA, 2017)

A Constituição Federal de 1946 proibiu as diferenças salariais pelo sexo do colaborador e criava ações de proteção à maternidade. (PEREIRA, 2017)

Em 1962, a Lei o 4.121, conhecida como Estatuto da Mulher Casada que o poder familiar continuou a ser exercido pelo homem, mas com a colaboração da mulher, devolvendo à sua condição de plena capacidade e revogando a possibilidade do marido ou pai de possuírem o direito de se oporem à realização do trabalho pela mulher. Posteriormente, a Constituição Federal de 1967 proibiu a discriminação nos critérios de admissão ao emprego por questões de sexo, estado civil e cor. (PEREIRA, 2017)

No final dos anos 1970, as mulheres iniciaram um processo de reflexão do seu papel e direitos na sociedade movimentos populares reivindicaram melhores salários, melhores condições de trabalho e de qualidade de vida. (PEREIRA, 2017)

Refletindo os anos 1970, a Constituição Federal de 1988 proibiu a discriminação tornando-se um dos objetivos da República: artigo 3ํㅗ. IV. O artigo $5^{\circ}$, I, abrange princípio da igualdade de gênero e 0 artigo $7^{\circ}$ proíbe a discriminação no âmbito laboral, confirmando a proibição de diferenças salariais, de exercício de funções e de critério de admissão por motivo do sexo, idade, cor ou estado civil. (BRASIL. Constituição (1988))

O trabalho noturno da mulher na indústria, nas minerações de subsolo, nas pedreiras, nas obras de construção civil e nas atividades perigosas e insalubres 
foram liberados com a revogação da Lei nำ 7.855/89 e no artigo 446, revogou-se o poder de interferência paternal e marital no contrato de trabalho da mulher.

A Lei no. 9.029/95, proibi a adoção de qualquer prática discriminatória e limitativa para ingresso ou sua manutenção no emprego, por motivo de sexo, origem, raça, cor, estado civil, situação familiar ou idade e também, especificamente à mulher, proibiu o rompimento do contrato de trabalho por qualquer motivo discriminatório, como possibilidade de penalização a readmissão com o ressarcimento integral das remunerações devidas durante todo o período de afastamento, ou a percepção em dobro, da remuneração do período de afastamento. A lei também declarou como crime a exigência de teste, indução à esterilização ou a estado de gravidez. (PEREIRA, 2017)

A Lei no 9.799/99, exigências ou recusa de candidatos pelo sexo ou pela gravidez e definiu formação profissional como fator determinante para definição da remuneração e ascensão profissional. (PEREIRA, 2017)

Por fim, a Lei no. 10.244/01 revogou o art. 376 da CLT, o qual limitava as horas-extras restando na legislação apenas normas protetivas da mulher sobre os aspectos físico e biológico. (PEREIRA, 2017)

A Convenção №. 100/1951, que trata sobre a igualdade de remuneração de homens e mulheres trabalhadores, a Convenção n‥ 111/1958, prescreve a igualdade de oportunidades e de tratamento em matéria de emprego ou profissão, visando eliminar a discriminação por razão do sexo e a Convenção no 127/67, que estabelece o peso máximo de carga para a mulher. (PEREIRA, 2017)

\subsection{O Trabalho da Mulher no Brasil}

Conforme apresentado no capítulo anterior, a Constituição Federal de 1988 e a CLT acrescentaram o princípio da igualdade, impedindo a discriminação por gênero, igualdade salarial e determinando as mesmas condições de admissão e tratamento igualitário no trabalho para homens e mulheres.

Ainda está presente a dicotomia entre homem-provedor e mulhercuidadora o que inferioriza a força de trabalho da mulher, sendo necessária apenas na falta somente na falta do homem provedor. Como consequência, a renda da mulher é vista como complementar, o que explica os salários reduzidos, assim como gera a visão destorcida do comprometimento da mulher, 
já que a mesma poderia abandonar o trabalho assim que houvesse um parceiro provedor. Além de que os custos decorrentes da maternidade muitas vezes impedem contratações e ascensão de mulheres dentro da sua carreira. (PEREIRA, 2017)

Confirmando o tema abordado, a "Women in Business 2015", estudo da empresa de auditoria e consultoria Grant Thornton, 57\% das empresas brasileiras não possuem mulheres em cargos de liderança. $O$ índice, bem acima da média global, de $32 \%$, coloca o Brasil na terceira posição que menos promovem mulheres para postos mais altos. O estudo apontou queda na porcentagem de mulheres líderes, de $28 \%$ em 2009 para 18\% em 2015, aliado ao número de empresas sem nenhuma mulher em cargos estratégicos cresce: no mesmo período, de 34\% para 53\%. (GRANT THORNTON, 2015)

O trabalho da mulher é uma dupla jornada, não só no Brasil. Constatou-se pela Organização Internacional do Trabalho, que as mulheres trabalham menos horas no emprego remunerado e são responsáveis por realizar em média, pelo menos duas vezes e meia mais tarefas domésticas não remuneradas, representando $57 \%$ das pessoas que trabalham tempo parcial. (OIT,2016). As mulheres trabalham em média 35 horas e meia e os homens 44 horas semanais, porém em trabalhos domésticos, a jornada chega a 21 horas e 12 minutos por semana para as mulheres, mais que o dobro da dos homens. Além disso, a Taxa de desemprego entre mulheres é de $15 \%$, bem acima dos $11,6 \%$ dos homens. (O GLOBO, 2016)

A gravidez também é outro aspecto da relação de trabalho da mulher já complicado conciliar o seu tempo no trabalho com o de cuidados com os seus filhos caso não haja a estrutura.

Podemos observar, que persistem no mundo do trabalho as desigualdades entre homens e mulheres; e por isso perpetuam as desvantagens às mulheres trabalhadoras em quesito de salários, ascensão funcional ou oportunidades de trabalho.

\subsection{As Principais Influencias na construção da visão da mulher}

\subsubsection{A Igreja}

A Igreja teve um papel muito importante na formação das relações sociais ao longo dos tempos, influenciando crenças e costumes. Muitos estereótipos de valorizar a liberdade masculina surgiram de conceitos religiosos, morais e legais 
que justificava a sua superioridade e seu domínio, ao que a mulher era considerada submissa, emocional, dependente do homem e voltada aos afazeres domésticos. (GARCIA, 2011)

Durante a Idade Média as mulheres tiveram um papel forte na Igreja Institucional e foram ganhando o seu espaço na cultura. (MURARO, 1995).

Após o ano 1200, o homem se tornou o centro do poder público, foram criadas leis escritas com direitos para os homens e deveres e restrições as mulheres, tudo com o reforço da penalização e julgamento dos doutores da Igreja e da Universidade. Nessa época, tudo que não estivesse controlado pela Igreja era considerado não ortodoxo e passível de extermínio, de forma paranoica. (GARCIA, 2011)

Por volta do século XIV as mulheres foram proibidas de praticar a medicina e só conseguiam trabalhar tendo um homem como responsável. Quem desafiasse as restrições era perseguido e exterminado. Muitas centenas de mulheres morreram em quatro séculos, sendo consideras bruxas, inferiores ou violadoras dos bons costumes. (GARCIA, 2011).

A Igreja possuía um clero que condenava as causas femininas e costumavam disseminar uma visão trágica e inferior das mulheres e da feminilidade, defendendo uma moral patriarcal. Nessa época se fixou a cultura patriarcal. (MURARO, 1995).

A instituição do casamento era reforçada pela Igreja como uma submissão da mulher ao homem, reduzindo a sexualidade da mulher apenas para fins de reprodução. (GARCIA, 2011)

\subsubsection{A Educação}

A formação do indivíduo é construída por fatores sociais, políticos e pelo seu contexto social, histórico e cultural. A definição de sexo e suas características também vem da educação e diferenciada de acordo com os costumes da sociedade, um exemplo é o menino aprender desde cedo a jogar futebol e a menina ganhar uma boneca. O mesmo acontece com a instituição do casamento, que era reforçada pela Igreja como uma submissão da mulher ao homem, reduzindo a sexualidade da mulher apenas para fins de reprodução. (GARCIA, 2011)

Para a educação feminina, a mulher é socializada e educada para fazer o papel de vítima, castrando as possibilidades de prazer feminino, tirando a 
ambição de crescimento e pregando a resignação do seu destino.(GARCIA, 2011).

Outro ponto importante é a formação da mulher como apoio para épocas de crise, sendo recompensa de forma precária devido a sua resignação. (GARCIA, 2011). Com o avanço da educação as mulheres estão saindo do posto de suporte para galgar novas carreiras ou opções antes delimitadas apenas para os homens.

A escolha da carreira geralmente é feita de acordo com a ideologia dos papeis do homem e da mulher vigente em nossa sociedade. Por isso, geralmente, a remuneração, o prestigio social e a ascensão social tendem a chamar a atenção dos homens ao escolher uma carreira e as mulheres tendem a dar valor a questões mais subjetivas como utilidade social da carreira e satisfação pessoal. (GARCIA, 2011)

Apesar do aumento da escolaridade das mulheres, as mesmas ainda se encontram nas profissões intermediárias (quadros administrativos de nível médio, técnicos, membros do corpo médico e social, etc.) sendo excluídas de cargos de autoridade e de responsabilidade, principalmente na área abordada nesse trabalho, como economia, finanças e na política. $O$ mesmo é percebido em termos de remuneração, onde continuam recebendo salários inferiores exercendo as mesmas funções, porém com maior escolaridade que os homens. (GARCIA, 2011)

\subsubsection{Os meios de comunicação e a publicidade}

Os meios de comunicação, agem como transmissor e doutrinador de modelos de comportamentos e padrões de comportamento em sociedade, consequentemente podendo atuar como fixador de estruturas sociais injustas e demais conceitos preconceituosos e discriminatórios. (GARCIA, 2011)

Os papéis sexuais são transmitidos pelos diferentes meios de comunicação, de forma estereotipada e discriminatória, apresentando a mulher como sedutora, porém dona de casa e mãe; o oposto ocorre com os homens que são apresentados como conquistador e muito profissionais. Basta perceber como a maioria das propagandas para produtos de casa, de limpeza, alimentos, adornos, perfumes, roupas e joias são feitas por mulheres recadas ou sensuais para encantar os consumidores masculinos. (CARTA CAPITAL, 2013) 
A mulher que trabalhava até pouco tempo atrás era mostrada como escassa e solteiras. Essa imagem era perpetuada pelos meios de comunicação em crianças e adultos, formando ideais profissionais estereotipados, exemplo: 0 menino é médico, a menina é enfermeira; o menino é astronauta, a menina é garçonete. (GARCIA, 2011)

Mesmo a conquista do espaço e respeito, as mulheres ainda rotuladas e discriminadas nas comunicações publicitárias e televisivas. Ainda há um apelo erótico com deslumbramento dos atributos físicos femininos, ex.: a menina de biquíni em comerciais de cerveja, o que pode ludibriar a mulher a achar que essa é a única possibilidade de obter um lugar de destaque na vida. (CARTA CAPITAL, 2013) 


\section{Métodos e procedimentos de coleta e de análise de dados do estudo}

O presente estudo é classificado de acordo com a taxonomia de Vergara (2010), quanto aos fins é uma pesquisa exploratória, pois busca ampliar o entendimento sobre um assunto ainda pouco desenvolvido. Sendo uma pesquisa exploratória, a abordagem utilizada foi a qualitativa. Quanto aos meios é uma pesquisa bibliográfica e também inclui um levantamento de campo, realizado através de entrevistas com 10 mulheres com duração de 30 minutos cada. As entrevistas tiveram como objetivo identificar e compreender fatores da equidade de gênero e da rotina das mulheres nas empresas do mercado financeiro.

A coleta de dados foi feita em duas etapas. A primeira etapa abrangeu uma pesquisa bibliográfica sobre o conteúdo de equidade de gênero e seus principais temas relacionados. A segunda etapa foi feita através de entrevistas semiestruturadas, guiadas por um roteiro de perguntas abertas, que está no anexo 1. O roteiro das entrevistas foi elaborado de acordo com o objetivo do trabalho e o tratamento dos dados foi feito através da leitura e interpretação das entrevistas, tratadas das seguintes formas: Transcrições, separação das respostas das entrevistadas por pergunta e interpretação dos dados das entrevistas.

A pesquisa foi direcionada às mulheres que ocupam ou ocuparam cargos no mercado financeiro, a fim de explorar suas perspectivas e sua visão sobre a realidade da mulher dentro desse mercado. Apesar de seguir um roteiro previamente formulado nas entrevistas, buscou-se explorar opiniões, pensamentos e estimular a expressão dos sentimentos das entrevistadas. Para complementar os resultados da pesquisa foram coletadas informações através de dados, documentos e relatórios da mulher no mercado de trabalho.

A abordagem qualitativa, utilizada pelo presente estudo, possui como uma das suas limitações a impossibilidade de generalizações, uma vez que a seleção dos sujeitos foi feita pelo critério de acessibilidade. Uma outra limitação é a interpretação dos resultados da entrevista com olhar pessoal do entrevistador, influenciando na análise dos dados. Supera-se essa limitação transcrevendo o discurso dos entrevistados e as frases ditas por eles. A vergonha de possíveis 
situações passadas ou medo do vazamento das informações foram limitações superadas deixando claro que as profissionais não seriam identificadas e que o nome de empresas e pessoas não eram necessários para o estudo. 


\section{Apresentação e análise dos resultados}

\subsection{Perfil das Entrevistadas}

As idades das entrevistadas variam entre 22 e 57 anos a maioria iniciou sua carreira jovem. Esse ingresso de profissionais cada vez mais jovens só está sendo possível graças a Lei no. 9.029/95, que proibi a adoção de qualquer prática discriminatória e limitativa para ingresso ou sua manutenção no emprego, por motivo de sexo, origem, raça, cor, estado civil, situação familiar ou idade. Esse ingresso cada vez mais cedo é apontado pelas entrevistadoras como forma de adquirir experiência e conhecimento para crescer no mercado de forma mais consistente e rápida.

Quanto ao estado civil das entrevistadas, possuímos apenas duas entrevistadas casadas (entrevistada 4 e 7) e uma viúva (entrevistada 3) e poucas possuem filhos. As mulheres apontaram que estão adiando um possível casamento ou gravidez justamente pelos custos decorrentes da maternidade que muitas vezes impedem as contratações e a ascensão de mulheres dentro da sua carreira. (PEREIRA, 2017).

No que diz respeito ao tempo de serviço na função, há uma discrepância muito grande entre as entrevistadas, porém conseguimos encontrar mulheres que permanecem na área por mais de 10 anos interruptos por qualquer retorno a família ou afastamento para cuidar de questões pessoais. Podemos com isso, desmistificar a visão destorcida do baixo comprometimento da mulher, já que a mesma poderia abandonar o trabalho assim que houvesse um parceiro provedor ou pretendesse ficar apenas com os cuidados da família. (PEREIRA)

A grande maioria das entrevistadas possuem curso superior completo e até são pós-graduadas a partir dos 24 anos. Confirma-se então que quanto maior o acesso à educação, que é o principal motor na transformação, maior a abertura das mulheres para carreiras ou opções antes delimitadas apenas para os homens. 


\subsubsection{Ingresso e a Ascensão Profissional}

A maioria das entrevistadas não acreditam que o processo de ingresso e ascensão profissional na empresa está disponível para todos, porém um pouco menos acessível para as mulheres, em função da cultura que ainda obriga a mulher a trabalhar mais e a cuidar mais da sua postura para ser considerada capaz de ingressar em áreas de topo ou mais técnicas.

"Não acredito que tenho menos oportunidade, mas acredito que tenho que ter muito mais atenção na minha postura e comportamento para ser respeitada. No ambiente profissional nós temos que prestar muito mais atenção em como vou me comportar e o que da minha posso abrir da vida pessoal para ser respeitada. Não acredito que seja uma falta de oportunidade, mas acredito que 0 meu esforço é maior do que outros homens no meu cargo para mostrar o meu valor. " (Entrevistada 9)

"Comercial e RH. Quanto maior o nível hierárquico ou técnico, menos mulheres possuem na área ou no cargo. " (Entrevistada 10)

Esse resultado foi apresentado nas nossas referências Bibliográficas que abrange o valor da comunicação (GARCIA, 2011) que cita o perfil de mulher que trabalhava como escassa, solteiras e estereotipadas em ideais profissionais estereotipados, o menino é médico, a menina é enfermeira; o menino é astronauta, a menina é garçonete. Esse modelo perpetua limites até no desejo de ascensão de profissional da mulher, já que as motivações para escolha da carreira geralmente são geradas de acordo com a ideologia vigente em nossa sociedade, sendo assim a remuneração, o prestigio social e a ascensão social tendem a chamar a atenção dos homens durante a escolha, já as mulheres se importam com questões mais subjetivas como utilidade social da carreira e satisfação pessoal. (GARCIA, 2011)

"Mas não acredito que nossa limitação seja mais algo inteiramente organizacional e sim comportamental. " (Entrevistada 9)

Além disso algumas entrevistas afirmam sentir poucas ou quase nenhuma barreira para o seu crescimento.

"Com certeza as oportunidades são dadas de acordo com a competência e preparo da pessoa, e não pelo sexo que ela possui. " (Entrevistada 2) 


\subsection{Diversidade de rendimentos}

Em todas as entrevistas as entrevistadas afirmam não perceber o estímulo a valorização da diversidade, porém uma das colaboradoras acredita que a entrada de novos funcionários está aos poucos estimulando a diversidade e valorizar mais a mulher.

"Na corretora não se fala muito nesses assuntos e vejo o RH bem tímido e bem ausente na verdade. Como a minha corretora é internacional, eu vejo que na sede em Londres isso é muito falado. Mas vejo sim, hoje uma vontade maior de abrir esse tema, visto que temos profissionais mais jovens e abertos na corretora. " (Entrevistada 9)

Para algumas das entrevistadas não há diferença ou que até as mulheres se beneficiam no comissionamento:

"Acho tem diferença de comissionamento de acordo com o cargo e a excelência do trabalho executado, meritocracia.'

Não vejo diferença no comissionamento comercial, ao contrário, muitas mulheres ganharam bônus expressivos usando de seu charme somados a sua inteligência na área comercial.

Porém, ainda vemos casos percebidos como discriminação salarial:

"Fui contratada para desempenhar uma função com salário superior ao do meu par, e apesar de demonstrar a qualidade do meu trabalho ser superior, o salário dele foi igualado. Acho que esse caso não teria ocorrido se eu fosse homem. Meu último bônus também foi igualado da mesma pessoa mesmo tendo desempenhado um trabalho de mais qualidade. " (Entrevistada 5)

\subsection{Equidade de gênero}

As entrevistadas possuem um entendimento sobre a equidade de gênero que abrange $o$ acesso a condições iguais para todos sem deixar de levar em conta a capacidade das pessoas; a equiparação das oportunidades, dos direitos e obrigações dentro da empresa independente de gênero.

"Mulheres e homens terem os mesmos direitos, isso não significa que devem ser tratados da mesma forma, pois possuem necessidades diferenciadas. Não sou tão radical a ponto de achar que as mulheres não devem deixar de receber gentilezas. Apenas acredito no respeito, pois precisamos fazer muito menos para ser desrespeitada." 
"Eu entendo que o valor da vaga deva ser proporcional a descrição da mesma, sem distinção do gênero. Acredito que o mercado financeiro ainda é machista, e a mulher precisa de impor, independe do nível hierárquico."

\subsection{A Valorização das Mulheres}

Uma parte das entrevistadas acredita que a valorização das mulheres tenha caráter estratégico para empresa, devido a suas características emocionais e pessoais, tais como organização, responsabilidade, resiliência e outros, conforme as transcrições das entrevistas abaixo:

Sim. Saber lidar com as dificuldades e diversidades, poder de decisão, resolução e resultado. (Entrevistada 1)

"Acredito que as características que mais são valorizadas nas empresas pela mulher é o fato da responsabilidade e organização. Ponderando que acho que homens podem ser também tão organizados e responsáveis. "

Podemos apontar o estudo publicado pela Bloomberg como uma confirmação desse olhar das mulheres: as mulheres costumam lidar melhor com as instabilidades do mercado financeiro, até em momentos conturbados. A Nutmeg analisou seis anos de mudanças bruscas de preço do FTSE 100 (FTSE The Index Company), e entre 50 mil investidores do Reino Unido, as investidoras tenderam a manter-se firmes durante eventos turbulentos como a dívida grega, em 2013, e a alta de juros nos Estados Unidos de fevereiro de 2018. (O GLOBO Economia, 2018)

As demais não visualizam qualquer tipo de valorização de qualquer característica como caráter estratégico para a empresa.

\subsection{Baixa Representação das Mulheres}

As mulheres entrevistadas acreditam ainda na baixa representatividade nas organizações e principalmente em cargos de liderança. A maioria nunca se perguntou o porquê da baixa representatividade, mas acreditam que é devido a uma série de fatores como a falta de ascensão por motivos discriminatórios e até a falta de confiança das próprias mulheres em insistir tais cargos.

"Eu vejo muitas mulheres são boas e estão há um tempo na vaga, todos gostam muito delas, mas não sei até que ponto a estagnação delas é pelo seu gênero. Mas acredito que ser mulher influencie, não que isso seja a única coisa". 
"Não conheço muitas mulheres no comando, mas não creio que seja por barreira no desenvolvimento e sim na entrada dessas mulheres na área. "

A maioria das entrevistadas nunca parou para pensar nos motivos pelos quais há uma baixa concentração de mulheres nas suas empresas, porém as mesmas não afirmam pelo seu sexo ou gênero. Inclusive, temos uma entrevistada que aponta como inexistente a dificuldade de ingresso nessa área apenas por ser mulher:

"Com certeza as oportunidades são dadas de acordo com a competência e preparo da pessoa, e não pelo sexo que ela possui. " Entrevistada 2

Podemos apontar então como causa a própria escolha da mulher, que acaba preferindo outras áreas consideradas mais ferminas do que a imagem agressiva do mercado de investimentos, conforme discorrido no texto sobre educação nas referências bibliográficas: As motivações para escolha da carreira geralmente são geradas de acordo com a ideologia vigente em nossa sociedade, sendo assim a remuneração, o prestigio social e a ascensão social tendem a chamar a atenção dos homens durante a escolha, já as mulheres se importam com questões mais subjetivas como utilidade social da carreira e satisfação pessoal. (GARCIA, 2011)

Outra questão a levar em conta com relação aos períodos que a mulher, caso não receba auxilio de seu parceiro, acaba se dedicando menos ou interrompendo o seu trabalho para cuidar de seus filhos ou demais problemas pessoais. Conversando abertamente com a entrevistada 2, soube que a mesma interrompeu o seu trabalho para cuidar de sua sogra a pedido de seu marido sendo liberada apenas após o falecimento do ente e do surgimento das dificuldades financeiras. Podemos então assumir que alguns conceitos sobre a instituição do casamento, que era reforçada pela Igreja como uma submissão da mulher ao homem na época Medieval, possui em seus rastros retardando o seu crescimento profissional. (GARCIA, 2011)

\subsection{Discriminação no Trabalho}

O tema que talvez fosse desconfortável e polêmico, foi um dos temas mais surpreendentes. No questionário, 6 das 10 mulheres entrevistadas afirmaram presenciar ou passar por alguma situação de discriminação no trabalho. Sendo que a grande maioria apontou seus pares ou a gestão intermediaria como responsáveis por esse tratamento. 
"Já ouvi uns comentários um pouco machistas, mas eram dos pares. Já vi, da parte dos gerentes intermediários inclusive sobre um funcionário homossexual. Mas acredito, que isso é muito por ele apresentar bem explicitamente sua sexualidade. Já vi dos nossos fornecedores, já presenciei comentários machista e dos demais comentários objetivando as mulheres. Mas não acredito que nossa limitação seja mais algo inteiramente organizacional e sim comportamental. " Entrevistada 9

Outros apontados como responsáveis por essa discriminação foram os envolvidos no desenvolvimento e manutenção de políticas de equidade de gênero como o $\mathrm{RH}$ e as própria mulheres.

"Sou alvo de preconceito até das próprias mulheres, que pedem a todo momento para eu parar de usar saia, mesmo que seja no joelho ou abaixo do joelho. Já recebi propostas e cantadas maliciosas de pares e gestores de nível médio. Quando eu namorava, sempre criticavam o meu namoro e davam a entender que eu estava perdendo estando comprometida. " Entrevistada 10

Essa falta de respeito pela mulher e a dificuldade de desassociar a mulher do erotismo vem principalmente dos meios de comunicação. O perfil de mulher que é transmitido e fixado é estereotipado e discriminatório, apresentando como sedutora, dona de casa e mãe, o oposto do homem que são apresentados como conquistador e profissional. Podemos citar como exemplo, dona-de-casa, em propagandas de produtos de limpeza, alimentos, adornos, ou a figura da mulher objeto sexual, anunciando perfumes, roupas e joias destinados a deslumbrar os homens (GARCIA, 2017) 


\section{Conclusões e recomendações para novos estudos}

O objetivo do presente estudo foi analisar as percepções, vivências e experiências das mulheres, tendo em consideração à igualdade de trabalho e oportunidades no Mercado Financeiro. Buscou-se entender e levantar à questão da percepção individual e pessoal das mulheres, para avaliar se a desigualdade é um fenómeno real e se há diferenças entre as áreas no mercado financeiro. $O$ objetivo foi comprido, à medida que se comprova que a grande maioria das mulheres entrevistadas não acredita que a discriminação seja o principal motivo para a pouca representatividade das mulheres no mercado financeiro ou para a sua ascensão. A grande maioria destaca a área comportamental das mulheres e a evolução da entrada no mercado como uma parte do obstáculo, sendo um desafio na educação e na difusão da imagem propagada das mulheres.

Após a análise das 10 entrevistas feitas, concluímos que evoluímos muito na recepção das mulheres no mercado financeiro, porém, ainda possuímos vieses de preconceitos na admissão e tratamento das colaboradoras. As mulheres ainda apontam divergências de tratamento, crescimento e remuneração confirmando estudos apontados na nossa bibliografia, as Taxa de assalariamento, em média, $75,0 \%$ do que os Homens ganham. Já para o crescimento profissional, $50,4 \%$ das mulheres estão empregadas setor privado com carteira, contra $72,4 \%$ do sexo masculino e a taxa de desemprego médio entre mulheres é mais alta do que entre homens (CARTA CAPITAL, 2018).

Porém, as mesmas definiram que a diferença não seria apenas vinda da discriminação, mas sim da consequência de as dificuldades da mulher galgar a sua carreira no mesmo ritmo e sem interrupção possuindo questões como tempo de afazeres domésticos e gravidez, conforme pesquisa. as mulheres trabalham em média 35 horas e meia e os homens 44 horas semanais, porém em trabalhos domésticos, a jornada chega a 21 horas e 12 minutos por semana para as mulheres, mais que o dobro da dos homens. Além disso, a Taxa de desemprego entre mulheres é de 15\%, bem acima dos $11,6 \%$ dos homens. (O GLOBO, 2016)

Quanto ao ingresso e ascensão a cargos de maior responsabilidade, a grande maioria não apresentou sentir discriminação direta, porém, acreditam que uma das justificativa na carreira da mulher é a falta de almejar tal objetivo. 
Podemos então entender que, a escolha da carreira geralmente é feita de acordo com a ideologia dos papeis do homem e da mulher vigente em nossa sociedade. Por isso, geralmente, a remuneração, o prestigio social e a ascensão social tendem a chamar a atenção dos homens ao escolher uma carreira e as mulheres tendem a dar valor a questões mais subjetivas como utilidade social da carreira e satisfação pessoal. (GARCIA, 2011).

A discriminação foi apontada pelas entrevistadas como algo ligado ao comportamento, em que as mulheres para serem respeitadas precisão empenhar muito mais esforço do que os homens. Vemos isso como uma forma de provar que os meio de comunicação e a própria educação dos papéis sexuais são transmitidos no brasil de forma estereotipada e discriminatória, apresentando a mulher como sedutora, porém dona de casa e mãe; o oposto ocorre com os homens que são apresentados como conquistador e muito profissionais. (CARTA CAPITAL, 2013). Esses estereótipos são exatamente o motivo pelo esforço das mulheres empregarem maiores esforços do que os homens para conquistar valor e respeito no seu trabalho e na sociedade.

Apesar de ainda existir discriminação que atrasa o ingresso e o crescimento das mulheres em determinadas áreas, muitas determinaram não ser esse o principal empecilho, sendo as próprias escolhas das mulheres que seriam menos competitivas e envesadas para ganhos materiais. Por isso, é importante que sejam feitos novos estudos sobre quais são os objetivos e atrativos na escolha da mulher ingressar e crescer em uma determinada carreira. Acredita-se que com esse estudo se verificará se as mulheres estão menos presentes em terminadas áreas ou hierarquias pela presença de um viés na sua escolha, conforme falado na influência da educação: A escolha da carreira geralmente é feita de acordo com a ideologia dos papeis do homem e da mulher vigente em nossa sociedade. Por isso, geralmente, a remuneração, o prestigio social e a ascensão social tendem a chamar a atenção dos homens ao escolher uma carreira e as mulheres tendem a dar valor a questões mais subjetivas como utilidade social da carreira e satisfação pessoal. (GARCIA, 2011) 


\section{Referências Bibliográficas}

ALBERTINI, R. Maioria das empresas brasileiras não tem mulheres em
cargos de liderança. Grant Thornton, 2015. Disponível em: <
https://www.grantthornton.com.br/grant-thornton-noticias/press-
releases/imprensa/women-in-business/>. Acesso em: 8 de outubro de 2005 .

ALMEIDA, C. ALBERTINI, D. C., R. Que horas ele chega? Mulher trabalha cada vez mais que homem. O Globo, 2018. Disponível em: $<$ https://oglobo.globo.com/economia/que-horas-ele-chega-mulher-trabalha-cadavez-mais-que-homem-18718278\#ixzz5WUM8cTWs>. Acesso em: 5 de novembro de 2018.

BNDES. Equidade de gênero e valorização da diversidade. Disponível em: $<$ https://www.bndes.gov.br/wps/portal/site/home/quem-somos/responsabilidadesocial-e-ambiental/o-que-fazemos/relacionamento-colaboradores/proequidade $>$. Acesso em: 12 de setembro 2018.

BRASIL. Constituição (1988). Brasília, Senado Federal, 1988.

CARNEIRO, L. Taxa de desemprego entre mulheres é de $15 \%$, bem acima dos $11,6 \%$ dos homens, aponta Ipea. O Globo, 25 jun. 2018. Disponível em: < https://oglobo.globo.com/economia/taxa-de-desemprego-entre-mulheres-de-15bem-acima-dos-116-dos-homens-aponta-ipea-22818080>. Acesso em: 5 de novembro de 2018.

DINO. Cresce o número de mulheres investidoras na Bolsa e no Tesouro Direto. Terra, 8 mar. 2018. Disponível em:

$<$ https://www.terra.com.br/noticias/dino/cresce-o-numero-de-mulheresinvestidoras-na-bolsa-e-no-tesourodireto,a6830ffaac46fcab3bda4664693c78bcg28o6bpe.htm>. Acesso em: 4 de outubro de 2018.

DINO. Protagonismo feminino no Mercado Financeiro ganha força. Estadão, 16 mar. 2017. Disponível em:

$<$ https://economia.estadao.com.br/noticias/releases-ae,protagonismo-femininono-mercado-financeiro-ganha-forca,70001701720>. Acesso em: 31 de outubro de 2018.

ESTADÃO CONTEÚDO. Brasil fica em 92 lugar entre 159 países em ranking de igualdade de gênero. Istoé, Basileia, 21 mar. 2017. Disponível em: < https://istoe.com.br/brasil-fica-em-92o-lugar-entre-159-paises-em-ranking-deigualdade-de-genero/>. Acesso em: 2 de novembro de 2018. 
GARCIA, C. O. A carreira da mulher no Banco Beta em busca da igualdade de oportunidades. Rio Grande do Sul, 2011. 59 p. Dissertação (Mestrado em Gestão de Negócios Financeiros) - Departamento de Administração: Universidade Federal do Rio Grande do Sul.

IPEA. Políticas Sociais: acompanhamento e análise. IPEA: Brasília, n. 22, 2014. p. 592-593.

ISTO É DINHEIRO. Mulheres no comando. 18 ago. 2018. Disponível em: <https://www.istoedinheiro.com.br/mulheres-no-comando/>. Acesso em: $12 \mathrm{de}$ setembro 2018.

KOMETANI, P. Mulheres ganham menos do que os homens em todos os cargos. G1, 7 mar. 2017. Disponível em:

<https://g1.globo.com/economia/concursos-e-emprego/noticia/mulheres-ganhammenos-do-que-os-homens-em-todos-os-cargos-diz-pesquisa.ghtml> Acesso em: 3 de novembro de 2018.

LAPA, N. A representação da mulher na mídia e em produtos. 18 dez. 2013. Disponível em: <https://www.cartacapital.com.br/blogs/feminismo-pra-que/arepresentacao-da-mulher-na-midia-e-em-produtos-7011.html>. Acesso em: 12 de setembro 2018

MURARO, R. M. A Mulher no Terceiro Milênio. Rio de Janeiro: Rosa dos Tempos, 1995.

O GLOBO. Pesquisa mostra que mulheres têm mais fibra para lidar com volatilidade no mercado financeiro, 2018 Disponível em:

$<$ https://oglobo.globo.com/economia/pesquisa-mostra-que-mulheres-tem-maisfibra-para-lidar-com-volatilidade-no-mercado-financeiro-22870775/>. Acesso em: 5 de setembro 2018.

OIT. Mulheres no Trabalho: tendências 2016. Genebra: OIT, 2016.

OIT BRASIL. Igualdade de gênero e raça no trabalho: avanços e desafios. Brasília: OIT, 2010, p. 11.

PEREIRA, R. P. O Assédio Moral nas Relações de Emprego Sob a Perspectiva das Relações de Gênero. Rio Grande do Sul, 2017. 61 p. TFCs (Graduação em Ciências Jurídicas e Sociais) - Departamento de Direito Público e Filosofia do Direito do Rio Grande do Sul.

REGO, A. Comprometimento Afetivo dos Membros Organizacionais: o Papel das Percepções de Justiça. Revista de Administração Contemporânea, v. 6, n.2, p. 209-241, 2002. 
ROLIM, L. N. A inserção da mulher no mercado de trabalho brasileiro. Carta Capital, 8 mar. 2018. Disponível em: <

https://www.cartacapital.com.br/blogs/brasil-debate/a-insercao-da-mulher-nomercado-de-trabalho-brasileiro >. Acesso em: 1 de novembro de 2018.

SANTOS, F. Mercado financeiro ainda é ambiente hostil para as mulheres; preconceito velado é desafio. Yahoo! Finanças, 7 mar. 2018. Disponível em: < https://br.financas.yahoo.com/noticias/mercado-financeiro-ainda-e-ambientehostil-para-mulheres-preconceito-velado-e-desafio-201417977.html >. Acesso em: 8 de outubro de 2018.

VEGARA, Sylvia Constant. Projetos e Relatórios de Pesquisa em Administração.12. ed. São Paulo: Atlas, 2010.

WENTZEL, M. Maior participação feminina traria $\mathbf{R} \$ \mathbf{3 8 2}$ bilhões à economia brasileira até 2025, diz OIT. Bbc Brasil, 14 junho. 2017. Disponível em: < https://www.bbc.com/portuguese/brasil-40281756>. Acesso em: 20 de outubro de 2018. 


\section{Anexo 1: Roteiro das Entrevistas}

1) Idade;

2) Estado civil;

3) Quantidade de filhos e idade;

4) Escolaridade;

5) Tempo de serviço no Mercado Financeiro;

6) Função atual;

7) Qual seu Vínculo Empregatício. Ex.: Contrato CLT, trabalhador por conta própria e estágio;

8) Tempo de serviço na função;

9) Você acredita que tenha mais ou menos oportunidade na carreira por ser mulher?

10) Como você avalia as oportunidades oferecidas às mulheres para a ascensão em suas carreiras?

11) Você acredita que existe o estímulo à valorização da diversidade nos processos de comissionamento dentro das empresas financeiras?;

12) Na sua organização os comportamentos de discriminação são por parte:

- Da gestão de topo;

- Da gestão intermédia;

- Dos pares;

- Não se verifica.

13) Comente a escolha acima com exemplos;

14) Como você enxerga a sua remuneração salarial diante da renda familiar? Complemento ou principal com os demais componentes da família?

15) O que você entende por equidade de gêneros? 
16) Você acredita que ter funcionárias mulheres é visto como caráter estratégico na organização? Quais caracterizas das mulheres são mais valorizadas nas empresas?

17) Quantas mulheres trabalham na sua área? É grande o número de mulheres na sua empresa?

18) Quais área você percebe maior quantidade de mulheres trabalhando?

19) Acha que as mulheres conseguem conciliar o trabalho com a vida pessoal? Porquê? 


\section{Anexo 2: Transcrição das Entrevistas}

\begin{tabular}{|c|c|c|c|c|c|c|c|c|}
\hline $\mathbf{N}^{\circ}$ entrevistada & Idade (anos) & Estado civil & $\begin{array}{l}\text { Quantidade de } \\
\text { filhos e idade }\end{array}$ & Escolaridade & $\begin{array}{l}\text { Tempo de serviço } \\
\text { no Mercado } \\
\text { Financeiro (anos) }\end{array}$ & Função atual & $\begin{array}{l}\text { Como é seu vinculo } \\
\text { empregatício? }\end{array}$ & $\begin{array}{l}\text { Tempo de serviço } \\
\text { na função (anos) }\end{array}$ \\
\hline 1 & 24 & Solteira & 0 & Superior Completo & 4 & Economista & Contrato CLT & 1,6 \\
\hline 2 & 38 & solteira & 0 & superior incompleto & 11 & $\begin{array}{c}\text { assistente } \\
\text { administrativa }\end{array}$ & Contrato CLT & 0,25 \\
\hline 3 & 57 & Viúva & 0 & Superior Completo & 20 & Comercial & Contrato CLT & 0,25 \\
\hline 4 & 22 & Solteira & 0 & $\begin{array}{l}\text { ensino médio } \\
\text { completo }\end{array}$ & 0,25 & Comercial & Estágio & 0,25 \\
\hline 5 & 37 & casada & $\begin{array}{c}1 \text { filho }-1 \text { ano e } 9 \\
\text { meses }\end{array}$ & 3 grau completo & 15 & sócia & $\begin{array}{l}\text { Trabalhador por conta } \\
\text { própria }\end{array}$ & 1 \\
\hline 7 & 38 & casada & 2 filhos ( 6 e 3 anos) & $\begin{array}{l}\text { nível superior } \\
\text { completo e pós } \\
\text { graduação }\end{array}$ & 13 & Jurídico & $\begin{array}{c}\text { Trabalhador por conta } \\
\text { própria }\end{array}$ & 0,15 \\
\hline 8 & 24 & Solteira & 0 & Pós-Graduada & 2 & $\begin{array}{l}\text { Assessora de } \\
\text { Investimento }\end{array}$ & $\begin{array}{c}\text { Trabalhador por conta } \\
\text { própria }\end{array}$ & 2 \\
\hline 9 & 23 & Solteira & 0 & Graduação completa & 0,25 & $\begin{array}{l}\text { Assistente de } \\
\text { Marketing }\end{array}$ & Contrato CLT & 0,25 \\
\hline 10 & 24 & Solteira & 0 & Graduação Incompleta & 5 & Comercial & $\begin{array}{c}\text { Trabalhador por conta } \\
\text { própria }\end{array}$ & 0,5 \\
\hline
\end{tabular}




\begin{tabular}{|c|c|c|}
\hline $\mathbf{N}^{\circ}$ entrevistada & $\begin{array}{l}\text { Você acredita que tenha mais ou menos } \\
\text { oportunidade na carreira por ser mulher? }\end{array}$ & $\begin{array}{c}\text { Como você avalia as oportunidades oferecidas } \\
\text { às mulheres para a ascensão em suas } \\
\text { carreiras? }\end{array}$ \\
\hline 1 & $\begin{array}{l}\text { No geral, acredito que as oportunidades ainda } \\
\text { são menores, apesar do mercado de trabalho } \\
\text { estar evoluindo. }\end{array}$ & $\begin{array}{l}\text { Não conheço empresas que tentam promover } \\
\text { equidade de gêneros e como o mercado } \\
\text { financeiro é majoritariamente liderado por } \\
\text { homens, há uma menor ascensão de mulheres a } \\
\text { cargos elevados. }\end{array}$ \\
\hline 2 & $\begin{array}{l}\text { Com certeza as oportunidades são dadas de } \\
\text { acordo com a competência e preparo da pessoa, } \\
\text { e não pelo sexo que ela possui. }\end{array}$ & $\begin{array}{l}\text { Vejo oportunidade de crescimento vinculado a } \\
\text { competência e merecimento, hoje em dia as } \\
\text { empresas visam lucro e competência para o } \\
\text { cargo, independente do gênero que está na } \\
\text { gestão. }\end{array}$ \\
\hline 3 & $\begin{array}{l}\text { Na área comercial do mercado financeiro, } \\
\text { principalmente na minha época, a maior parte da } \\
\text { equipe era formada por mulheres, era difícil } \\
\text { encontrar homens nesse ramo. Porém, tirando as } \\
\text { parte mais administrativas, a maior parte do } \\
\text { mercado financeiro era e continua sendo composta } \\
\text { por homens. Ainda passamos por preconceitos para } \\
\text { entrar e permanecer nesse mercado }\end{array}$ & $\begin{array}{l}\text { Não conheço muitas mulheres no comando, mas } \\
\text { não creio que seja por barreira no } \\
\text { desenvolvimento e sim na entrada dessas } \\
\text { mulheres na área. }\end{array}$ \\
\hline 4 & menos & $\begin{array}{l}\text { Não, na verdade me sinto até meio isolada no } \\
\text { trabalho. }\end{array}$ \\
\hline 5 & Menos oportunidades & $\begin{array}{c}\text { Em regra geral, são baixas, já que em algum período } \\
\text { da vida laboral, a mulher tem filhos e precisa } \\
\text { dividir a atenção entre trabalho e família }\end{array}$ \\
\hline 6 & $\begin{array}{l}\text { No mundo em que vivemos hoje, acredito que a } \\
\text { mulher tem mais chances. }\end{array}$ & $\begin{array}{c}\text { Não vejo com bons olhos, pois as vezes parece que } \\
\text { as mulheres são julgadas mais pela aparência do } \\
\text { que pela competência. }\end{array}$ \\
\hline 7 & $\begin{array}{l}\text { acredito que tive menos oportunidades em me } \\
\text { recolocar por ser mulher, com quase } 40 \text { anos e dois } \\
\text { filhos pequeno }\end{array}$ & $\begin{array}{l}\text { eu acho que são mais escassas em relação às } \\
\text { oportunidades oferecidas para os homens }\end{array}$ \\
\hline 8 & Menos oportunidade & $\begin{array}{l}\text { Acredito que tenha melhorado bastante nos } \\
\text { últimos anos, mas ainda estamos longe do ideal a } \\
\text { ser alcançado. }\end{array}$ \\
\hline 9 & $\begin{array}{l}\text { não acredito que tenho menos oportunidade, mas } \\
\text { acredito que tenho que ter muito mais atenção na } \\
\text { minha postura e comportamento para ser } \\
\text { respeitada. No ambiente profissional nós temos } \\
\text { que prestar muito mais atenção para ser } \\
\text { respeitada, como vou comportar e o que da minha } \\
\text { vida pessoal eu vou abrir. Não acredito que seja } \\
\text { uma falta de oportunidade, mas acredito que o } \\
\text { meu esforço é maior para mostrar o meu valor. }\end{array}$ & $\begin{array}{l}\text { Eu beijo muitas mulheres são boas e estão há um } \\
\text { tempo na vaga, todos gostam muito delas, mas não } \\
\text { sei ate que ponto a estagnação delas é pelo seu } \\
\text { gênero. Mas acredito que ser mulher influencie, } \\
\text { não que isso seja a única coisa }\end{array}$ \\
\hline 10 & $\begin{array}{l}\text { Acredito que em áreas mais importantes eu tenho } \\
\text { menos oportunidade, porém na área comercial eu } \\
\text { tenho maior facilidade por questões estéticas, por } \\
\text { ser mulher, mais empática e etc. }\end{array}$ & $\begin{array}{l}\text { Muito poucas, quando o assunto começa a ficar } \\
\text { mais técnico ou com maior responsabilidade eu me } \\
\text { sinto um pouco mais excluída. }\end{array}$ \\
\hline
\end{tabular}




\begin{tabular}{|c|c|c|}
\hline $\mathbf{N}^{\circ}$ entrevistada & $\begin{array}{l}\text { Você acredita que existe o estímulo à } \\
\text { valorização da diversidade nos processos de } \\
\text { comissionamento dentro das empresas } \\
\text { financeiras? }\end{array}$ & $\begin{array}{l}\text { No mercado Financeiro os comportamentos } \\
\text { de discriminação são por parte: }\end{array}$ \\
\hline 1 & Não & Não se verifica \\
\hline 2 & $\begin{array}{l}\text { Acho tem diferença de comissionamento } \\
\text { de acordo com o cargo e a excelência do } \\
\text { trabalho executado, meritocracia. }\end{array}$ & Não se verifica \\
\hline 3 & $\begin{array}{l}\text { Não vejo diferença no comissionamento } \\
\text { comercial, ao contrario, muitas mulheres } \\
\text { ganharam bônus expressivos usando de seu } \\
\text { charme somados a sua inteligência na área } \\
\text { comercial. }\end{array}$ & $\begin{array}{l}\text { Dos Pares e principalmente dos clientes e } \\
\text { outros relacionamentos que possuímos no } \\
\text { trabalho }\end{array}$ \\
\hline 4 & Da gestão de topo & $\begin{array}{l}\text { Forma de tratamento e piadas de cunho } \\
\text { machista com tom de brincadeira }\end{array}$ \\
\hline 5 & Não acredito. & Da gestão de topo \\
\hline 6 & Sim & Não se verifica. \\
\hline 7 & $\operatorname{sim}$ & $\begin{array}{l}\text { atualmente entendo que não há. Na empresa } \\
\text { anterior havia discriminação por um gerente } \\
\text { dentro do próprio RH que falava que mulher } \\
\text { fica grávida, tira meses de licença } \\
\text { maternidade etc., que isso atrapalha }\end{array}$ \\
\hline 8 & $\begin{array}{l}\text { Dependendo da empresa sim, mas a grande } \\
\text { maioria infelizmente não. }\end{array}$ & Não se verifica. \\
\hline 9 & \begin{tabular}{|} 
Na corretora não se fala muito nesses \\
assuntos e vejo o RH bem tímido e bem \\
ausente na verdade. Como na minha \\
corretora é internacional, eu vejo que na \\
sede em Londres isso é muito falado na \\
corretora. Mas vejo hoje uma vontade maior \\
de abrir esse tema, visto que temos \\
profissionais mais jovens e abertos na \\
corretora.
\end{tabular} & Gestão intermediaria e dos pares. \\
\hline 10 & $\begin{array}{l}\text { Não acho que seja algo observado no } \\
\text { mercado financeiro. Acredito que eles não se } \\
\text { importem tanto com isso. Porém, hoje na } \\
\text { minha empresa estão entrando pessoas } \\
\text { novas possuem uma consciência sobre }\end{array}$ & da gestão intermediária e dos pares \\
\hline
\end{tabular}




\begin{tabular}{|c|c|}
\hline $\mathbf{N}^{\circ}$ entrevistada & Comente a anterior \\
\hline 1 & \\
\hline 2 & \\
\hline 3 & \\
\hline 4 & \\
\hline 5 & $\begin{array}{l}\text { Fui contratada para desempenhar uma função com salário superior ao do meu par, e } \\
\text { apesar de demonstrar a qualidade do meu trabalho ser superior, o salário dele foi } \\
\text { igualado. Acho que esse caso não teria ocorrido se eu fosse homem. Meu último bônus } \\
\text { também foi igualado da mesma pessoa mesmo tendo desempenhado um trabalho de } \\
\text { mais qualidade. }\end{array}$ \\
\hline 6 & Não se aplica. \\
\hline 7 & \\
\hline 8 & No meu trabalho, graças a Deus, não presenciei nenhuma situação de discriminação. \\
\hline 9 & $\begin{array}{l}\text { Já ouvi uns comentários um pouco machistas, mas eram dos pares. Já vi, da parte dos } \\
\text { gerentes intermediários inclusive sobre um funcionário homossexual. Mas acredito, } \\
\text { que isso é muito por ele apresentar bem explicitamente sua sexualidade. Já ouvi dos } \\
\text { nossos fornecedores e dos demais comentários machistas comentários objetivando as } \\
\text { mulheres. Mas não acredito que a nossa limitação seja algo inteiramente } \\
\text { organizacional e sim comportamental. Eu sempre fui muito simpática e houve situações } \\
\text { que meus pares não souberam diferenciar essa simpática de interesse pessoal. } \\
\text { Acredito que nós mulheres temos que prestar atenção no nosso comportamento o } \\
\text { tempo todo para preservar o mesmo respeito que os homens possuem naturalmente. }\end{array}$ \\
\hline 10 & $\begin{array}{l}\text { Sou alvo de preconceito até das próprias mulheres, que pedem a todo momento para } \\
\text { eu parar de usar saia, mesmo que seja no joelho ou abaixo do joelho. Já recebi } \\
\text { propostas e cantadas maliciosas de pares e gestores de nível médio. Quando eu } \\
\text { namorava, sempre criticavam o meu namoro e davam a entender que eu estava } \\
\text { perdendo estando comprometida }\end{array}$ \\
\hline
\end{tabular}




\begin{tabular}{|c|c|c|}
\hline entrevistada & $\begin{array}{l}\text { Como você enxerga a sua remuneração salarial diante da renda } \\
\text { familiar? Complemento ou principal com os demais componentes da }\end{array}$ & $\begin{array}{l}\text { O que você entende por equidade de gêneros e qual é o entendimento } \\
\text { das organizações sobre o papel da mulher no Mercado Financeiro? }\end{array}$ \\
\hline 1 & Não se aplica. Moro sozinha. & $\begin{array}{l}\text { Entendo como igualdade de direitos/deveres. Dentro das empresas, isto } \\
\text { deveria ser verificado em oportunidades igualitárias, valorizando }\end{array}$ \\
\hline 2 & Renda complementar & $\begin{array}{l}\text { Equidade de gênero se refere a um tratamento igual para ambos os sexos } \\
\text { em relação a qualquer tipo de atividade, seja na área trabalhista, de } \\
\text { oportunidades, etc. Hoje o mercado enxerga a mulher muito melhor que } \\
\text { em uns anos pois sempre foi um ambiente masculinizado, mas com } \\
\text { competência e altivez a mulher foi conquistando seu espaço e } \\
\text { quebrando barreiras de um pré-conceito determinante e injusto } \\
\text {,colocando competentes gestoras em lugar de destaque. }\end{array}$ \\
\hline 3 & Principal & $\begin{array}{l}\text { Entendo como equidade de gênero a total possibilidade de você ser quem } \\
\text { você quiser sem nenhuma barreira levantada por qualquer julgamento }\end{array}$ \\
\hline 4 & Renda complementar & $\begin{array}{l}\text { Direitos iguais entre homem e mulher. Deveria ser a mesma função e salário } \\
\text {, mas isso não ocorre }\end{array}$ \\
\hline 5 & Complemento & $\begin{array}{l}\text { Eu entendo que o valor da vaga deva ser proporcional a descrição da mesma, } \\
\text { sem distinção do gênero. Acredito que o mercado financeiro ainda é } \\
\text { machista, e a mulher precisa de impor, independe do nível hierárquico. }\end{array}$ \\
\hline 6 & Muito abaixo da média. Complemento com o da família. & $\begin{array}{l}\text { Entendo que seja a forma de tratamento igualitário entre o homem e a } \\
\text { mulher. Aída existem muitas empresas que valorizam mais os homens do }\end{array}$ \\
\hline 7 & principal & nãoé \\
\hline 8 & $\begin{array}{l}\text { Recebo o mesmo salário que os homens da minha empresa. Na verdade, } \\
\text { somos remunerados de acordo com a nossa carteira de clientes, sendo } \\
\text { assim, não tendo nenhuma distinção. }\end{array}$ & $\begin{array}{l}\text { Entendo que equidade de gênero é onde mulheres e homens são tratados } \\
\text { da mesma forma. Não havendo distinção salarial, horas de trabalho, entre } \\
\text { outros fatores. Acredito que a mulher tem ganho um destaque maior no } \\
\text { mercado financeiro, mas ainda precisamos evoluir mais nesse ponto. } \\
\text { Principalmente em cargos mais altos, ainda se vê poucas mulheres. }\end{array}$ \\
\hline 9 & $\begin{array}{c}\text { Não contribuo explicitamente com a renda família, utilizo apenas para cobrir } \\
\text { os meus gastos pessoais. }\end{array}$ & $\begin{array}{l}\text { Mulheres e homens terem os mesmos direitos, isso não significa que } \\
\text { devem ser tratados da mesma forma, pois possuem necessidades } \\
\text { diferenciadas. Não sou tão radical a ponto de achar que as mulheres não } \\
\text { devem deixar de receber gentilezas. Apenas acredito no respeito, pois } \\
\text { precisamos fazer muito menos para ser desrespeitada. }\end{array}$ \\
\hline 10 & Eu me sustento sozinha & $\begin{array}{l}\text { Entendo como equidade de gênero a total possibilidade de você ser quem } \\
\text { você quiser sem nenhuma barreira levantada por qualquer julgamento }\end{array}$ \\
\hline
\end{tabular}




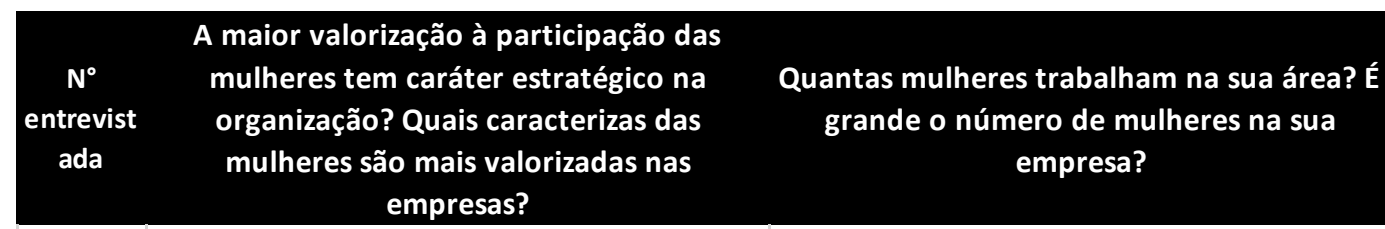

No meu ponto de vista, são poucos os esforços das empresas de promover equidade de gênero nas equipes. Apesar disso, as características valorizadas são semelhantes 2. Na empresa são 4. uma vez que a mulher já esteja inserida no mercado financeiro.

Vamos ser honestos, mulitas empresas usam a figura feminina e seus atributos para vender seus produtos, como a beleza por exemplo. $\mathrm{E}$ muitas empresas usam mulheres para vender os produtos que, muitas das vezes, são utilizados por mulheres. Ainda existe muito marketing apelativo pois os homes são muito atraídos pelo visual e o marketing das empresas sabem muito bem explorar isso.

Em uma empresa com 15 funcionários, possuímos 5 mulheres, no caso $1 / 3$ do quadro. Em mercado financeiro isso é uma vitória pois era um meio dominado pela presença masculina.
Com a minha experiência sempre vi as mulheres em área em que seu principal objetivo é o relacionamento seja com os clientes, seja com os parceiros. Sei que somos escolhidas pelo beleza física e pela delicadeza, mas também acredito que somos mais calmas, pacientes, empáticas e por isso conseguimos manter-nos próximas daqueles que são interessantes para a empresa Sim, Cooperação, trabalho em equipe e flexibilidade

Não, Responsabilidade, integridade e

5 competência.

Sim. Saber lidar com as dificuldades e

6 diversidades, poder de decisão, resolução e resultado.

7 comprometimento, facilidade de adaptação a novas situações, sensibilidade Acredito que as características que mais são valorizadas nas empresas pela mulher é o fato da

8 responsabilidade e organização. Ponderando que acho que homens podem ser também tão organizados e responsáveis.

Nunca vi as mulheres serem tomada como

9 estratégia. Eu já fui ouvida por ser mulher e por ser jovem.

Acredito que além de sermos mais empáticas e calmas, só o fato de ser mulher e bonita, principalmente na área comercial, abre muitas portas para a própria empresa.
Não chega um terço na empresa geral, porém na área comercial estamos em 3 mulheres contra 1 homem

Uma. Não

2, Não, é minoria.

Somente eu. Sim, na minha empresa trabalham mais mulheres do que homens.

2, porém vejo mais homens na empresa como um todo

Não é tão grande. Gostaria que fossem maior, atualmente somos 5 mulheres e 20 homens.

Na minha área do marketing só tem eu de mulher, mas são suas pessoas. Então não é muito grande a amostra por base de comparação. Mas eu percebo que quando mais alto o nível hierárquico e mais alto o nível técnico, menor a quantidade de mulheres.

$\mathrm{Na}$ área comercial há bem mais mulheres do que nas áreas técnicas, porém nós temos que ter muito mais cuidado com a nossa imagem do que os homens. 


\begin{tabular}{|c|c|c|}
\hline $\mathbf{N}^{\circ}$ entrevistada & $\begin{array}{l}\text { Quais área você percebe maior quantidade } \\
\text { de mulheres trabalhando? }\end{array}$ & $\begin{array}{c}\text { Acha que as pessoas têm facilidade em } \\
\text { conjugar o trabalho com a vida pessoal? } \\
\text { Porquê? }\end{array}$ \\
\hline 1 & Administrativo / Comercial / Econômico & $\begin{array}{l}\text { Acho que o mercado financeiro demanda mais } \\
\text { tempo de dedicação/trabalho comparado a outras } \\
\text { áreas de atuação. No entanto, acredito ser } \\
\text { completamente possível conjugar o trabalho com } \\
\text { a vida pessoal, ainda que com menor facilidade } \\
\text { comparativamente. }\end{array}$ \\
\hline 2 & Comercial, administrativo & $\begin{array}{l}\text { É difícil ainda mais sendo mulher e mãe pois por } \\
\text { mais que o mercado esteja mais aberto as } \\
\text { mulheres, elas que abraçam todos os problemas } \\
\text { familiares, cuidando do filho doente, indo a } \\
\text { reuniões escolares, e tomando conta da casa de } \\
\text { uma maneira geral e isso impacta } \\
\text { consideravelmente em seu trabalho. Fato que não } \\
\text { acontece muito no ambiente masculino }\end{array}$ \\
\hline 3 & Comercial & $\begin{array}{l}\text { Nunca tive problemas em conciliar os dois, } \\
\text { quando eu não podia estar em casa por qualquer } \\
\text { compromisso de trabalho o meu marido também } \\
\text { estava em algum outro compromisso de trabalho }\end{array}$ \\
\hline 4 & RH e BackOffice & $\begin{array}{l}\text { Não. Porque para fazer ou focar em algo tem q } \\
\text { abrir mão de um dos dois temporariamente. }\end{array}$ \\
\hline 5 & $\begin{array}{l}\text { Jurídico, contabilidade, atendimento ao cliente, } \\
\text { sustentabilidade. }\end{array}$ & Sim, desde que compromisso para os dois lados. \\
\hline 6 & $\begin{array}{l}\text { Áreas contábil, jurídica, administrativa, recepção, } \\
\text { RH, entre outras. }\end{array}$ & Sim \\
\hline 7 & nas áreas de RH, administrativo & $\begin{array}{l}\text { com certeza sim pois ninguém consegue se } \\
\text { realizar como pessoa sem conseguir equilibrar } \\
\text { vida pessoal e profissional. Acho que tudo tem } \\
\text { que estar interligado e em equilíbrio }\end{array}$ \\
\hline 8 & $\begin{array}{l}\text { Como todos aqui desempenham a mesma função, } \\
\text { não consigo responder essa pergunta. }\end{array}$ & $\begin{array}{l}\text { Em sua maioria sim. Eu pelo menos costumo } \\
\text { conjugar o meu trabalho, com vida pessoal e } \\
\text { estudos. Acho que equilibro é a palavra certa. }\end{array}$ \\
\hline 9 & $\begin{array}{l}\text { Atendimento e comercial são áreas com uma } \\
\text { presença feminina mais alta. }\end{array}$ & $\begin{array}{l}\text { Via de regra, eu vejo que as pessoas são bem } \\
\text { humanas nisso, eles acreditam que é } \\
\text { compreensível as vezes por exemplo você as } \\
\text { vezes desligar do trabalho justamente por } \\
\text { prender a maior parte do horário comercial. } \\
\text { Embora eu ainda veja um pouco de dificuldade } \\
\text { para quem tem filho. }\end{array}$ \\
\hline 10 & $\begin{array}{l}\text { Comercial e RH. Quanto maior o nível hierárquico } \\
\text { ou técnico, menos mulheres possuem na área ou } \\
\text { no cargo. }\end{array}$ & $\begin{array}{l}\text { Muito difícil, porém dá quando é solteira, ao casar } \\
\text { e ter filhos a situação fica um pouco mais } \\
\text { complicada. }\end{array}$ \\
\hline
\end{tabular}

